\title{
The Research of the Continuance Intention of students to Use Tourism APP —Based on the TPB Model
}

\author{
Shuo Feng \\ Tourism, hospitality and event management / Business / University of Queensland / 4072
}

\begin{abstract}
Recently, the intelligent tourism has become increasingly popular in tourism industry. Particularly, the tourism APP has become an important and convenient channel for tourists to make travel decisions and take relevant behaviors. The paper mainly researches the continuously using intention of customers to tourism APP among five dimensions (the behavioral intention, the subject norms, the perceived behavioral control, the past behavior and the behavioral attitude) through the theory of planned behavior model. Besides, this paper chooses the college students in Dalian, China as the research object of study and provides a research reference for tourism APP companies.
\end{abstract}

\section{Introduction}

The increasing disposable income and transportation development provide people more chance to travel. In addition, China online tourism market has continuously grown in recent years (CNNIC, 2017). In 2011, the sum of business transaction in China online tourism market is only 10.62 billion yuan; in 2016, this sum reaches 26.27 billion yuan; by the end of 2017, this number is predicted to over 80 billion yuan (Forward-looking Industry Research Institute, 2016). Specifically, the number of China clients who order relevant tourism products like tickets and hotels through the mobile terminal have reached 266 billion people in 2016, and the growth rate of phone using for tourism use has increased from $33.9 \%$ in 2015 to $37.7 \%$ in 2016 (CNNIC, 2017).

Students, particularly the college student group has become an emerging market in tourism industry. More than half of the students at college got the tourism information on the internet, and college students prefer mobile phone APP as the channel to browse tourism information. At present, there are many types of travel APPs and the relevant market competition is fierce. How to keep the stickiness of college students' behaviors and make them continuously use the same APP can help APPs better occupy this specific market and maintain corporate competitiveness.

Therefore, it is meaningful to analyze the influencing factors about the continuous using behavior of college students for an APP. Some scholars use the theory of reasoned action (TRA) (Fishbein M, 1975), the theory of planned behavior (TPB) (Ajzen, 1991), the technology acceptance model (TAM) (Davis FD, 1989) and the innovation diffusion theory (IDT) to research consumer behavior. According to previous studies, this article uses these theories above to study and analyze the factors that affect consumers' continued use of the same app.

\section{Literature Review}

\subsection{Theory of Continuous Intention}

Continuous using intention is defined by the users' satisfaction with information system use and perceived usefulness of continued information system use (Bhattacherjee A, 2001), which means the intention that customers are willing to steadily use the information system in a long-term. In fact, the rapid development of mobile internet makes more and more research focus on the importance of customers' information behavior in the field of information system. According to the time of usage, users' behavior can be divided into two stages, which is initial usage and continuous usage (Huangfu Qinghong, 2013). For a successful information system, the initial accept behavior is only the first step, the key factor is keeping customer continuously using the information system (Bhattacherjee A, 2008). Because users' tourism behavior tends not to be frequent, considering how to maintain the high-level users' continuous usage in the tourism APP is important for operators. In the following passage, the theory of planned behavior model will be raised.

\subsection{Theory of Planned Behavior Model (TPB)}

The source of TPB can be dated back to Fishbein's Theory of Multi-attribute Attitude. Fishbein thought that behavioral attitude determined behavioral intention (BI), while anticipative behavioral result and the outcome evaluation determined the behavioral attitude. According to Fishbein's (1975) and Ajzen's (1991) relevant research, TRA was born (Fishbein M, 1975). This theory showed that behavioral attitude and subjective norms 
directly influence the BI, while BI directly determine the real action. However, TRA is not always effective because that it regards behavior as the result of a completely individual will. In fact, most behaviors in real life depend on not only individual subjective factors but also personal capability and their surrounding conditions (Wicker A W, 1969). Therefore, in 1985, Azjen added the variate of perceived behavioral control (PBC) to improve the TPB (Ajzen, 1985).

In recent years, TPB has been the important theory to explain and predict personal behavior decision in the field of social psychology. Particularly, in the tourism industry TPB is applied more to the behavior intention of offline tourism products (Sparks, 2007) and tourism destination (Lam, 2006). Particularly, the influencing factors of college student's behavior intention about continuously using the tourism APP will be researched in this paper and the mature TPB model combining with the subject of tourism APP will be applied as well.

\section{Research Design}

\subsection{Hypothetical Raising}

According to previous researches, this paper shows that customer's continuous use behavior will be influenced by 5 variates including behavioral attitude, perceived behavioral control (PBC), subject norms, past behavior and behavioral intention.

\subsubsection{Behavioral Attitude}

Behavior attitude (BA) is defined as the degree assessment whether a person is or not fond of executing some behaviors, which can influence the personal expectation for the positive or negative attribute of the outcome (Fishbein\&Ajzen, 1975). As the most powerful predictor of $\mathrm{BI}$, a positive personal attitude means a greater personal intention for executing behaviors, while more negative BA means smaller intention (Ajzen, 1991). In this paper, when the college student's attitude for using tourism APP is positive, they tend to continuously use them (Huangfu Qinghong, 2013). Therefore, this article hypothesizes that BA plays a middle adjusting role in the process that the subject norms and perceived behavioral control influence the BI, and the following hypothesis can be built.

H1: Behavior attitude positively influences the students' BI of continuously using tourism APP.

\subsubsection{Subject Norms}

Subject norm (SN) is the social stress felt by a person when this person executes some specific behaviors (Terry et al., 1999). This means that the individual behavioral decision-making is influenced by their surrounding people and organization. More supports from those surrounding important people and organization means greater executing intention of personal behavioral (Ajzen, 1991). People who belong to different groups in society tend to reinforce their group identity by following group norms (Terry et al., 1999).
Higher degree of group identity will influence the individual SN more from the group environment stress, which means that the person with high identity lean to obey the group norms to make behavioral decision (Sparks\&Shepherd, 1992). In this research, SN refers to the stress from the reference group faced by students when they continuously use tourism APP, and this paper will reveal whether the college students' participative behavior is influenced by their surrounding important people and organization as well. In other words, when the students recognize that their surrounding important people and organization continuously use tourism APP, they tend to follow the relevant behaviors. Therefore, the following hypothesis can be built.

H2: Subject norm positively influence the students' $\mathrm{BI}$ of continuously using tourism APP.

\subsubsection{Perceived Behavioral Control}

Perceived Behavioral Control (PBC) reflects the influence of personal behavior from real control condition (Rodgers, 2008). Individual behavior also depends on the individual's obtaining for objective factors including its resource like money, chance, time and individual capability and skills. Student's behavior for continuously using tourism APP partly depends on their disposable time, money or other resource, and students with ideal conditions are likely to continuously use tourism APP. Therefore, the following hypothesis can be built.

H3: Perceived Behavioral Control positively influences student's BI of continuously using tourism APP.

\subsubsection{Past Behavior}

As the research shows, past behavior (PB) and past experience have an important influence in the individual decision-making behavior, people with acquainted experience lean to do effective behavior. After using tourism APP at the first time, the positive using experience can promote students to use again. The hypothesis can be built.

H4: Past behavior positively influence students' BI of continuously using tourism APP.

To sum up, the research builds the following hypothesis model:

$$
\mathrm{BI}=\mathrm{a} 1 \mathrm{SN}+\mathrm{a} 2 \mathrm{PBC}+\mathrm{a} 3 \mathrm{BA}+\mathrm{a} 4 \mathrm{~PB}
$$

\subsubsection{Sample Choice and Questionnaire Design}

In this study, I choose the students in Dalian as the object of study and choose the random selection to launch the questionnaire survey. The questionnaire is divided into 5 dimensions, which are BA, SN, PBC, PB and BI. Specifically, BA includes 2 questions, SN includes 2 questions, PBC includes 1 question with 7 items, PB includes 2 questions, BI includes 2 questions. This questionnaire adopts Likert Five-point Scale to inquiry and grade, students' evaluation for tourism APP is divided into 5 grades as $1=$ extremely useful, $2=$ more 
useful, 3=general, 4=less useful, 5=extremely useless; the students' self-identity intention of the reason of initial using of tourism APP is divided into $1=$ strongly agree, 2=more agree, 3=general, 4=less agree, $5=$ disagree. For the aspect of student's life decision-making and their satisfying experience for tourism APP, this questionnaire adopts 5-point grade, which means 1-5 grades represent different score proportion.

In this questionnaire, several scales for measuring different dimensions are adapted, which include the scale for measuring BA (Ajzen\&Fishbein, 1980), BI, SN (Yoon C, 2011), PBC (Davis F D, 1989) and PB.

Table 1: Designing Scale of Questionnaire of Continuously Using Tourism APP

\begin{tabular}{|c|c|c|c|}
\hline Variate & $\begin{array}{c}\text { The } \\
\text { Number of } \\
\text { Questions }\end{array}$ & Items & Reference \\
\hline Demographics & 2 & Gender, Grade & $\begin{array}{c}\text { Demographic } \\
\text { Classified Standard }\end{array}$ \\
\hline Past Behavior & 2 & $\begin{array}{c}\text { (1) The Average Travel Times Each Year } \\
\text { (2) The Happiness of Using A Tourism APP in The Past }\end{array}$ & Davis, 1989 \\
\hline Behavioral Attitude & 2 & $\begin{array}{c}\text { (1) What is your recommendation for a tourism APP? } \\
\text { (2)What is the sum of consumption on a tourism APP? }\end{array}$ & $\begin{array}{c}\text { Ajzen, 1991 } \\
\text { Yoon, 2011 }\end{array}$ \\
\hline $\begin{array}{c}\text { Subjective Norms } \\
\text { (1) The Tendency of Surrounding People to Recommend A } \\
\text { (2) The Motivation of Initially Using A Tourism APP }\end{array}$ & $\begin{array}{c}\text { Rodgers, 2008 } \\
\text { Davis, 1989 }\end{array}$ \\
\hline $\begin{array}{c}\text { Perceived Behavioral } \\
\text { Control }\end{array}$ & 2 & $\begin{array}{c}\text { (1) If tourism APP can influence the daily life decision? } \\
\text { promote continuously using? (include } \text { items) } \\
\text { (2) The satisfied using experience can promote continuously } \\
\text { using. }\end{array}$ & $\begin{array}{c}\text { Bhattacherjee A, } \\
2001\end{array}$ \\
\hline
\end{tabular}

\subsection{Data Collection}

There have 2 ways to collect the data: (1) Handing out questionnaires to investigate the students who used tourism APP. (2) Finding the available user date from tourism e-commerce. The investigated sample in the group of Dalian college students is chosen through SO JUMP, so the recovery efficiency of the questionnaire can be ensured. The pre-investigation granted 50 questionnaires and collected 46 questionnaires in January $10^{\text {th }}, 2017$. After analyzing the data, the final questionnaire was confirmed through sending out 450 questionnaires and collecting 417 questionnaires from February $20^{\text {th }}$ to May $10^{\text {th }}$ in 2017 . In the process of collecting the final questionnaire, there have 276 valid questionnaires and 141 invalid questionnaires, the recovery rate is $92.67 \%$ and the valid recovery rate is $61.33 \%$. In all valid questionnaires, all of the investigated objectives are the college students in universities in Dalian, and this investigating conform to the research topic and study object.

\section{Empirical Analysis}

\subsection{Basic Statistics}

In the 276 valid questionnaires, the questionnaire shows the senior students $(64.13 \%)$ and the female students $(56.52 \%)$ are the main group. For the average travel times, more than half of all participants $(53.26 \%)$ tend to travel once or twice a year. $34.78 \%$ students think tourism APP is extreme useful, and $50.00 \%$ students more agree with that Tourism APP is useful. 76.09\% students think surrounding people will recommend a tourism APP.

For the APP using reason, the most participant students $(38.04 \%)$ extremely agree that tourism APP is convenient and time-saving. $48.91 \%$ participants more agree that the recommendation from surrounding people is a major motivation factor to initially use a tourism APP. However, 20.65\% students also think the advertising and promotion of a tourism APP is not a major reason to use a tourism APP (Figure 1). 


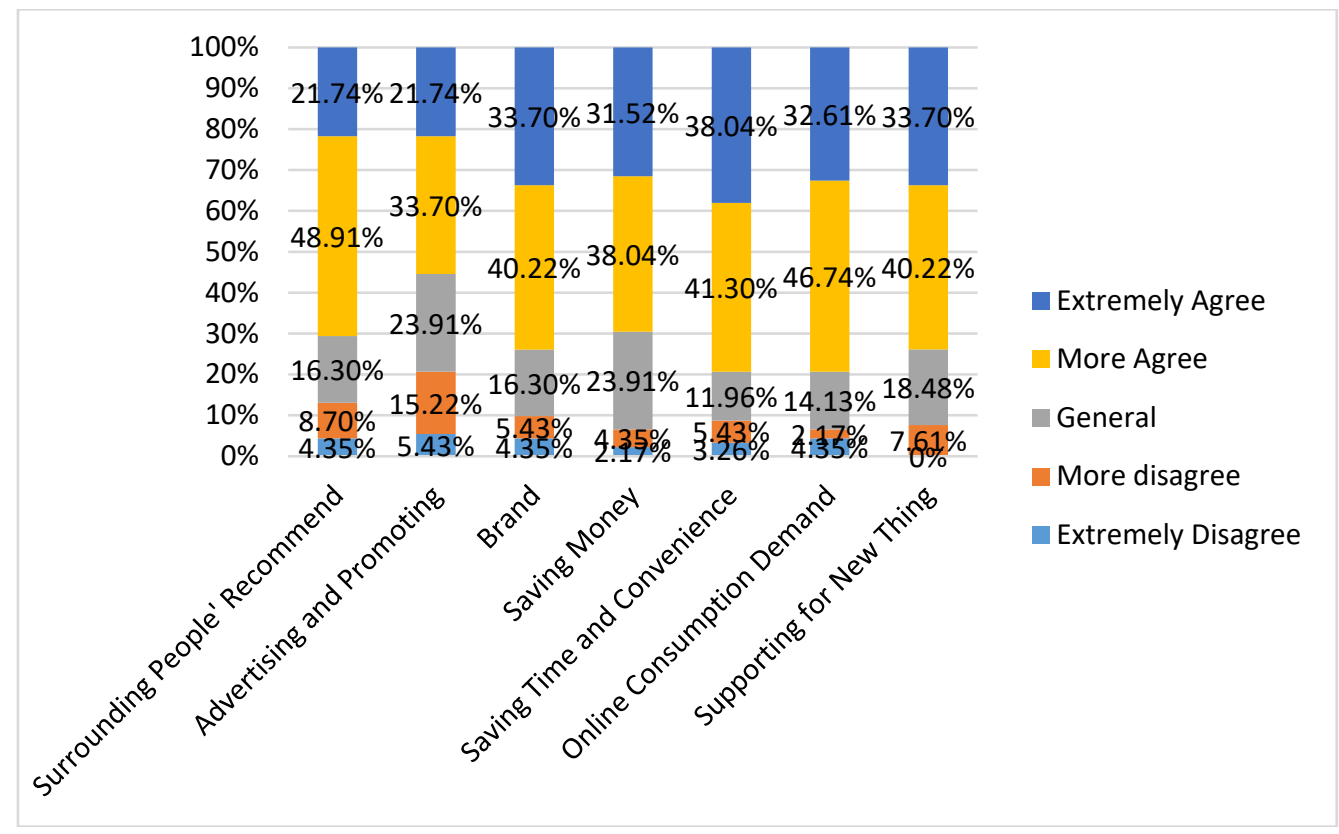

Figure 1 The Reason of the Initial Using of Tourism APP

For the choice of mainstream tourism APP brand, the most participant students (79.35\%) tend to choose Ctrip (CTRP), and the second popular brand of tourism APP is Qunar with 63.04\% people choosing. Other brands like Tuniu (35.87\%), Dianping (35.87\%), Tongcheng (26.09\%) and Fliggy (14.13\%) also attract some students. Particularly, the hotel APPs such as Hanting Hotel APP attracts $13.04 \%$ participants and the traffic APP such as Spring Airlines APP attract $10.87 \%$ people.
For the decision-making about how daily life can be influenced by a tourism APP, the most participant students $(42.39 \%)$ mark 5 point for the choice of accommodation, and the average score of these items reaches 4.11. Besides, the average score of the choice of catering or food and the choice of traffic are both 3.89 . On the contrary, the lowest average score is 3.48 for the choice of shopping (Figure 2).

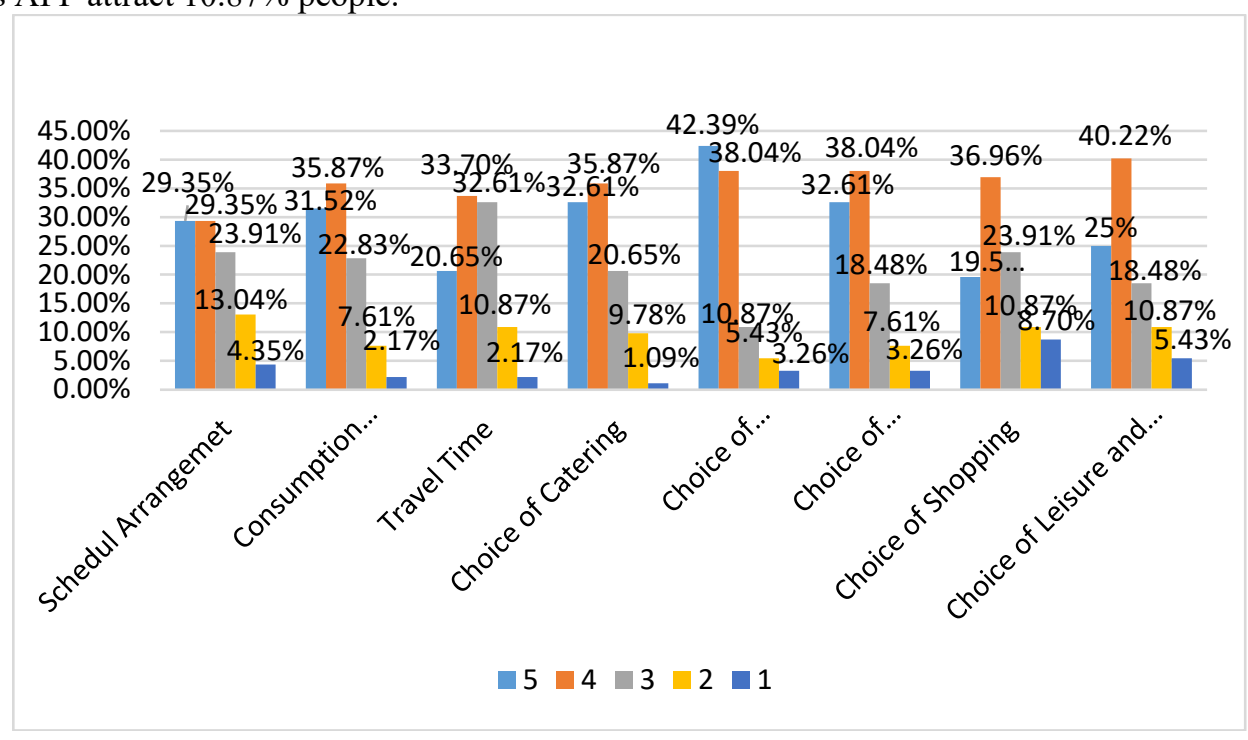

Figure 2 The Decision Making about Tourism APP in Daily Life

$97.83 \%$ people who tend to continuously use a tourism APP have a previous satisfactory experience. Specifically, the most students $(61.96 \%)$ mark 5 point for the comprehensive information and timely update of a tourism APP, the average score of the high safety and reliability of tourism APP is 4.29. The lowest average score is 3.9 for the aspect of beautiful interface and convenient browse (Figure 3). 


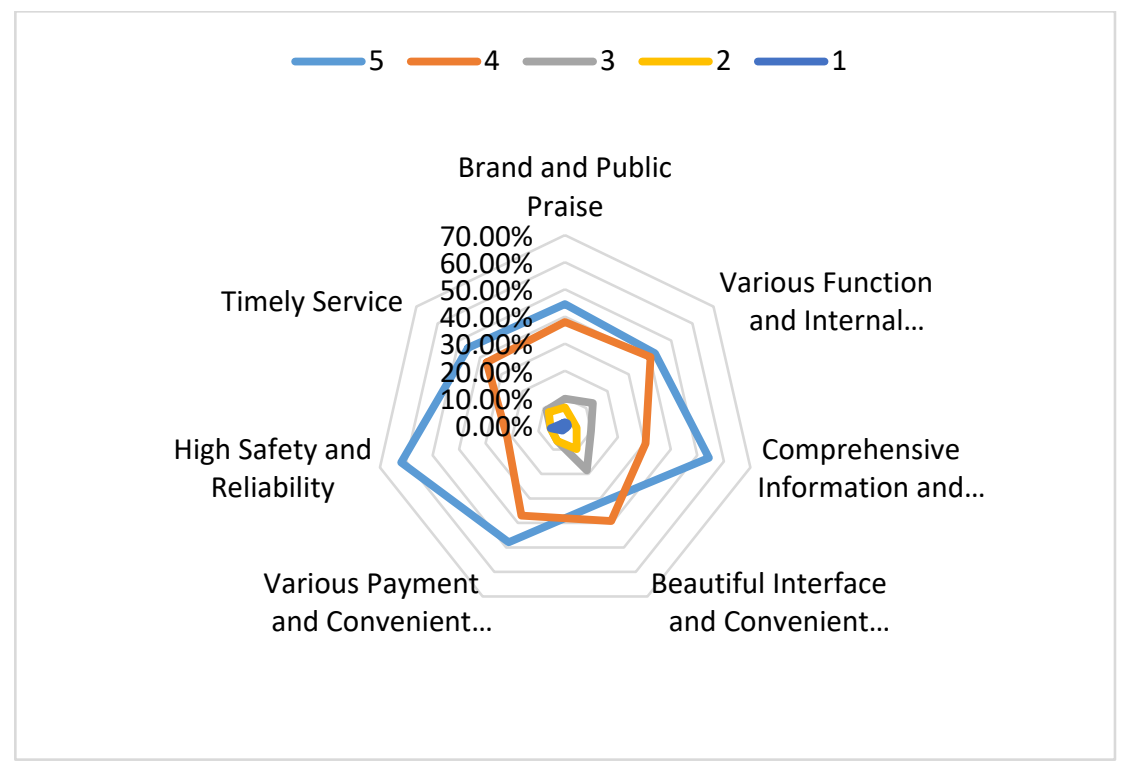

Figure 3 The Satisfactory Experience of Attracting Continuous Customers

\subsection{Exploratory Factory Analysis}

\subsubsection{The Reliability Analysis and Validity Test}

In order to test whether the data result from the questionnaire collection is consistent, the method of Cronbach's Alpha coefficient is adopted. The reliability test for the data from questionnaires will be conducted by using SPSS 17.0. As the table 2 shows, the overall reliability of this questionnaire $\alpha$ is 0.940 which is greater than 0.6 , so the overall reliability of this questionnaire $\alpha$ is higher, and the reliability of the data is more ideal. Furthermore, the validity analysis can measure the validity of the questionnaire and its measuring factors, and the result of validity analysis can reflect the result of measuring questionnaire. This paper uses the factor analysis to conduct the analysis of the structure validity through the test of KMO and Bartlett sphere inspection. The metric of KMO is 0.893 , which is more than 0.8 , so the validity is better; the approximate chi-square of Bartlett sphere inspection is 5831.443, $\mathrm{P}$-value is 0.000 , which pass the significant test (the significant bit is $1 \%$ ). Therefore, the data of questionnaire among each topic has a certain correlation, and the questionnaire can be analyzed by the factor analysis.

Table 2: The Reliability Statistics and KMO and Bartlett Sphere Inspection

\begin{tabular}{|c|c|c|c|c|c|}
\hline $\begin{array}{c}\text { Cronbach's } \\
\text { Alpha }\end{array}$ & \multirow{2}{*}{$\begin{array}{c}\text { Number } \\
\text { of Items }\end{array}$} & $\begin{array}{c}\text { Sampling enough Kaiser-Meyer-Olkin } \\
\text { metric }\end{array}$ & \multicolumn{3}{|c|}{ Bartlett Sphere Inspection } \\
\cline { 3 - 5 } & 28 & 0.893 & The approximate chi-square & df & Sig. \\
\hline 0.940 & 28 & 5831.443 & 378 & 0.000 \\
\hline
\end{tabular}

\subsubsection{Common Factor Extraction}

As the table 3 shows, there have 5 factors that its initial eigenvalue is more than 1 , and the variation explained variance is 67.346 . In the 28 items, extracting 5 factors has a high representation for the initial data. According to the Scree criterion, this broken line become flat after integrate 5 , so in the 28 items, extracting 5 factors is appropriate.

Table 3: The Total Explained Variance

\begin{tabular}{|c|c|c|c|c|c|c|c|c|c|}
\hline \multirow{2}{*}{$\begin{array}{l}\text { Ing } \\
\text { redi } \\
\text { ent }\end{array}$} & \multicolumn{3}{|c|}{ Initial Eigenvalues } & \multicolumn{3}{|c|}{ Loading the Extraction of Sum of Square } & \multicolumn{3}{|c|}{$\begin{array}{c}\text { Loading the Rotation of Sum of } \\
\text { Square }\end{array}$} \\
\hline & $\begin{array}{c}\text { Sum } \\
\text { matio } \\
\mathrm{n}\end{array}$ & $\begin{array}{c}\text { Percentage } \\
\text { of } \\
\text { Variance }\end{array}$ & $\begin{array}{c}\text { accumulate } \\
d \\
\text { percentage }\end{array}$ & $\underset{n}{\text { Summatio }}$ & $\begin{array}{l}\text { Percentage } \\
\text { of Variance }\end{array}$ & $\begin{array}{c}\text { accumulate } \\
\mathrm{d} \\
\text { Percentage }\end{array}$ & $\begin{array}{c}\text { Sum } \\
\text { matio } \\
\text { n }\end{array}$ & $\begin{array}{c}\text { Percentage } \\
\text { of } \\
\text { Variance }\end{array}$ & $\begin{array}{l}\text { accumulated } \\
\text { Percentage }\end{array}$ \\
\hline 1 & $\begin{array}{c}11.53 \\
0\end{array}$ & 41.179 & 41.179 & 11.530 & 41.179 & 41.179 & 5.551 & 19.825 & 19.825 \\
\hline 2 & 2.516 & 8.987 & 50.166 & 2.516 & 8.987 & 50.166 & 5.328 & 19.029 & 38.854 \\
\hline 3 & 2.132 & 7.615 & 57.781 & 2.132 & 7.615 & 57.781 & 4.674 & 16.692 & 55.546 \\
\hline 4 & 1.427 & 5.097 & 62.878 & 1.427 & 5.097 & 62.878 & 1.677 & 5.988 & 61.533 \\
\hline 5 & 1.251 & 4.468 & 67.346 & 1.251 & 4.468 & 67.346 & 1.627 & 5.812 & 67.346 \\
\hline
\end{tabular}


The table 4 shows the rotating component matrix with the factorial attribution of each title. Title 7 has 8 aspects $-7(1)$ to $7(8)$, which belong to factor 1 with the title 8 , and the load factor is more than 0.5 . Thus, title 7 and title 8 can be categorized to the dimension of BI. Title 9 has 7 aspects that belong to factor 2 and the load factors are more than 0.5 . Title 9 thus can be categorized to the dimension of PBC. Title 5 has 7 aspects that belong to factor 3 with the title 4 , and the load factor is more than 0.5 . These two titles thus are categorized to the dimension of SN. The title 14 and title 10 both belong to factor 4 , and the load factor is more than 0.8 , so these two titles can be categorized to the dimension of PB. Title 3 and title 13 both belong to factor 5, and the load factor is more than 0.7 , so these two titles can be categorized to the dimension of BA. Above all, the result of data validity and factor extracting is ideal, and further research can be proceeded.

Table 4: Rotating Component Matrix

\begin{tabular}{|c|c|c|c|c|c|}
\hline \multirow{2}{*}{ Title } & \multicolumn{5}{|c|}{ Component } \\
\hline & 1 & 2 & 3 & 4 & 5 \\
\hline $\begin{array}{c}\text { 7(8) The tourism can influence your decision for leisure and } \\
\text { recreation }\end{array}$ & 0.832 & & & & \\
\hline 7(7). The tourism can influence your decision for shopping choice & 0.817 & & & & \\
\hline $\begin{array}{l}\text { 7(4). The tourism can influence your decision for the choice of } \\
\text { restaurant }\end{array}$ & 0.746 & & & & \\
\hline $\begin{array}{l}\text { 7(1). The tourism can influence your decision in your life (the } \\
\text { arrangement of travel schedule) }\end{array}$ & 0.713 & & & & \\
\hline $\begin{array}{l}\text { 7(2). The tourism can influence your decision in your life (travel } \\
\text { consumption expenditures) }\end{array}$ & 0.704 & & & & \\
\hline 7(3). The tourism can influence your decision for the time to travel & 0.689 & & & & \\
\hline $\begin{array}{l}\text { 7(6). The tourism can influence your decision for the choice of } \\
\text { transportation }\end{array}$ & 0.684 & & & & \\
\hline $\begin{array}{l}\text { 7(5). The tourism can influence your decision for the choice of } \\
\text { hotel }\end{array}$ & 0.619 & & & & \\
\hline $\begin{array}{l}\text { 8. Can you continuously use a tourism APP because of the } \\
\text { satisfying experience on it? }\end{array}$ & 0.575 & & & & \\
\hline $\begin{array}{l}\text { 9(6). You will continuously use a tourism APP because of the } \\
\text { satisfying experience about ... (safe, authentic and reliable) }\end{array}$ & & 0.854 & & & \\
\hline $\begin{array}{l}\text { 9(5). You will continuously use a tourism APP because of the } \\
\text { satisfying experience about... (various modes of payment, } \\
\text { convenient ordering) }\end{array}$ & & 0.807 & & & \\
\hline $\begin{array}{l}\text { 9(3). You will continuously use a tourism APP because of the } \\
\text { satisfying experience about... (comprehensive information, timely } \\
\text { update) }\end{array}$ & & 0.803 & & & \\
\hline $\begin{array}{l}\text { 9(7). You will continuously use a tourism APP because of the } \\
\text { satisfying experience about... (timely customer service, better } \\
\text { after-sales service) }\end{array}$ & & 0.768 & & & \\
\hline $\begin{array}{l}\text { 9(4). You will continuously use a tourism APP because of the } \\
\text { satisfying experience about... (appealing interface, convenient } \\
\text { browsing) }\end{array}$ & & 0.749 & & & \\
\hline $\begin{array}{l}\text { 9(2). You will continuously use a tourism APP because of the } \\
\text { satisfying experience about... (multiple functions and various } \\
\text { products) }\end{array}$ & & 0.711 & & & \\
\hline $\begin{array}{l}\text { 9(1). You will continuously use a tourism APP because of the } \\
\text { satisfying experience about... (better brand and public praise, high } \\
\text { customer loyalty) }\end{array}$ & & 0.592 & & & \\
\hline $\begin{array}{c}\text { 5(7). The reason that you initially use a tourism APP is... (Trying } \\
\text { and supporting the new thing) }\end{array}$ & & & 0.728 & & \\
\hline $\begin{array}{l}5(4) \text {. The reason that you initially use a tourism APP is... (most } \\
\text { tourism APP can save money (no middlemen make the difference)) }\end{array}$ & & & 0.724 & & \\
\hline $\begin{array}{l}\text { 5(5). The reason that you initially use a tourism APP is... (most } \\
\text { tourism APP is convenience and it can save time) }\end{array}$ & & & 0.705 & & \\
\hline $\begin{array}{l}5(2) \text {. The reason that you initially use a tourism APP is... (the } \\
\text { advertising promotion and function introduction of this tourism } \\
\text { APP) }\end{array}$ & & & 0.690 & & \\
\hline
\end{tabular}


5(3). The reason that you initially use a tourism APP is... (better brand and public praise of this tourism APP)

5(6). The reason that you initially use a tourism APP is... (self-requirement of online using and consumption)

5(1). The reason that you initially use a tourism APP is... (the recommendation from your surrounding family, classmate and friend)

4. Did your surrounding people recommend a tourism APP for you? 10. Your average travel time is each year

14. Was it happy for you to use a tourism APP in the past? 13. Your sum of consumption on the tourism APP 3. Your evaluation for tourism APP

The table 5 shows the $\alpha$ value of various dimensions are all more than 0.6. Particularly, the $\alpha$ value of BI is 0.919 ; the $\alpha$ value of $\mathrm{PB}$ is 0.703 ; the $\alpha$ value of behavioral is 0.649 ; the $\alpha$ value of PB is 0.703 ; the $\alpha$ value of $\mathrm{SN}$ is 0.878 ; the $\alpha$ value of $\mathrm{PBC}$ is 0.925 . The data illustrates that the reliability of various dimensions is effective and all reach the ideal level.

Table 5: Reliability Test

\begin{tabular}{|c|c|c|}
\hline Dimension & Inclusive Items & Cronbach's Alpha \\
\hline Behavioral Intention & 9 & 0.919 \\
\hline Past Behavior & 2 & 0.703 \\
\hline Behavioral Attitude & 2 & 0.649 \\
\hline Subject Norms & 8 & 0.878 \\
\hline $\begin{array}{c}\text { Perceived Behavioral } \\
\text { Control }\end{array}$ & 7 & 0.925 \\
\hline
\end{tabular}

\subsection{Confirmatory factor analysis and hypothesis testing}

Using the SPSS 17.0, regarding the behavior intention as the dependent variable, regarding the $\mathrm{PB}, \mathrm{SN}, \mathrm{BA}$ and $\mathrm{PBC}$ as the independent variables, this research will use enter regression to conduct the fitting analysis of multiple linear regression (MLR). The tables 6 shows the $\mathrm{R}$ square is 0.495 , $\mathrm{R}$ square of adjusting is 0.488 , so the degree of fitting of model is good, which means the degree of explanation model for the original data is good. In this table, the $\mathrm{F}$ value is $66.435, \mathrm{P}$ value is $0.000(\mathrm{P}<$ 0.01 ), so this model with a statistical significance passes the significance testing with the $1 \%$ significant level.

Table 6: Model Fitting Parameters

\begin{tabular}{|c|c|c|c|c|c|}
\hline $\mathrm{R}$ & R Square & $\begin{array}{c}\text { R Square of } \\
\text { Adjusting }\end{array}$ & $\begin{array}{c}\text { The estimated } \\
\text { standard error }\end{array}$ & F & Sig. \\
\hline $.704^{\mathrm{a}}$ & .495 & .488 & 4.48079 & 66.435 & $.000^{\mathrm{a}}$ \\
\hline
\end{tabular}

As the table 7 of regression coefficient shows, $\mathrm{SN}$, $\mathrm{PBC}$ and $\mathrm{BA}$ all have a significant positive impact on the dependent variable - BI $(\mathrm{P}<0.05)$.

Therefore, behavioral intention $=0.361 *$ subject norms $+0.374 *$ perceived behavioral control + $0.110 *$ behavior attitude

The standard regression coefficient of $\mathrm{SN}$ is 0.631 , the $\mathrm{T}$ value of $\mathrm{T}$ test is $6.280, \mathrm{P}$ value is $0.000(\mathrm{P}<0.01)$.
Therefore, SN has a significant positive impact on the BI. The standard regression coefficient of $\mathrm{PBC}$ is 0.374 , the $\mathrm{T}$ value of $\mathrm{T}$ test is $6.893, \mathrm{P}$ value is $0.000(\mathrm{P}<0.01)$. Therefore, the $\mathrm{PBC}$ has a significant positive impact on the BI. The standard regression coefficient of $\mathrm{BA}$ is 0.110 , the $\mathrm{T}$ value of $\mathrm{T}$ test is $2.341, \mathrm{P}$ value is 0.020 $(\mathrm{P}<0.05)$. Therefore, the $\mathrm{BA}$ has a significant positive impact on the BI.

Table 7: Regression Coefficient

\begin{tabular}{|c|c|c|c|c|c|c|}
\hline \multirow{2}{*}{\multicolumn{2}{|c|}{ Model }} & \multicolumn{2}{|c|}{$\begin{array}{l}\text { Unstandardized } \\
\text { Coefficients }\end{array}$} & \multirow{2}{*}{$\begin{array}{c}\text { Standardized } \\
\text { Coefficients } \\
\text { Trial }\end{array}$} & \multirow{2}{*}{$\mathrm{t}$} & \multirow{2}{*}{ Sig. } \\
\hline & & B & $\begin{array}{l}\text { Standard } \\
\text { Error }\end{array}$ & & & \\
\hline \multirow{3}{*}{$\begin{array}{l}\text { Dependent } \\
\text { Variable: } \\
\text { Behavioral }\end{array}$} & (Constant) & 4.351 & 1.349 & & 3.224 & 0.001 \\
\hline & Past Behavior & 0.120 & 0.245 & 0.022 & 0.489 & 0.625 \\
\hline & Subject Norms & 0.423 & 0.067 & 0.361 & 6.280 & 0.000 \\
\hline
\end{tabular}




\begin{tabular}{|c|c|c|c|c|c|c|}
\multirow{3}{*}{ Intention } & $\begin{array}{c}\text { Perceived Behavioral } \\
\text { Control }\end{array}$ & 0.423 & 0.061 & 0.374 & 6.893 & 0.000 \\
\cline { 2 - 7 } & Behavioral Attitude & 0.500 & 0.214 & 0.110 & 2.341 & 0.020 \\
\hline
\end{tabular}

The standard regression coefficient can judge the degree of influence of independent variables for the dependent variable - BI. Particularly, the perceive behavioral control has the biggest impact on the BI, followed by SN, BA again. According to the correlation analysis, the three dimensions above have a significant correlation with the $\mathrm{BI}$, so the $\mathrm{H} 1, \mathrm{H} 2$ and $\mathrm{H} 3$ are validate.

\section{Conclusion and Discussion}

Based on the empirical study for 276 students, this paper researches the continuously using intention of students for tourism APP. Particularly, it analyzes five different dimensions about behavioral attitude, behavioral intention, past behavior, subject norms and perceived behavioral control.

Through the verification, $\mathrm{SN}$ is positively correlated with BI. Particularly, the reason that students initially use the tourism APP and the recommendation from students' surrounding people have a significant positively impact on the continuously using intention. Thus, the APP internal convenient functions and the external word of mouth from surrounding potential customers should be considered. Furthermore, PBC is positively correlated with BI. Particularly, the satisfactory experience from a tourism APP such as information gathering has a significant positive impact on the continuously using intention. Therefore, tourism APP should collect more valuable information such as the price of various hotels or the time schedule of traffic. In addition, the safety issues such as the safe payment, the information reliability and the risk management are equally important for continuous customers. Tourism APP will be advised to improve student's using experience to enhance its competitiveness, attract new student customers and keep existing customer loyalty. However, this paper only chooses the college students as the study object, which causes the limitation of statistical sample and the incomprehensive research result as well.

\section{Reference}

1. Ajzen, I. (1985), "From intentions to actions: A theory of planned behavior. In: Kuhl J, Beckman J, (Eds.), Action control: From cognition to behavior", Heidelberg, Germany, Springer, pp. 11 39.

2. Ajzen, I. (1991), "The theory of planned behavior", Organizational Behavior and Human Decision Processes, vol. 50, no. 2, pp. 179-211.

3. Bhattacherjee, A. (2001), “Understanding information systems continuance: An expectation-confirmation model", MIS Quarterly, vol. 25 , no. 3 , pp. 351-370.

4. Bhattacherjee, A., Perols, J. And Sanford, C. (2008), "Information technology continuance: A theoretic extension and empirical test", Journal of Computer Information System, vol. 30, no. 4, pp. 17-26.
5. CNNIC. (2017), "The $39^{\text {th }}$ statistical report on internet development in China", China Internet Network Information Center, Beijing.

6. Davis, F.D. (1989), "Perceived usefulness, perceived ease of use, and user acceptance of information technology", IT Usefulness and ease of use, vol. 13, no. 3, pp. 319-340.

7. Fishbein, M. and Ajzen, I. (1975), "Belief, attitude, intention and behavior: an introduction to theory and research", Reading, MA: Addison-Wesley, pp. 335-383.

8. Forward-looking Industry Research Institute. (2016), "The report of the development prospect of china online tourism industry and investment strategy plan".

9. Huangfu, Q.H. (2013), “A review of domestic and foreign researches on information systems continuance-based on literature research of electronic service and other related fields", Journal of Information, vol. 32, no.10, pp. 111-116.

10. Lam, T. and Hsu, H.C. (2006), "Predicting behavioral intention of choosing at ravel destination", Tourism Management, vol. 27, no. 4, pp. 589-599.

11. Rodgers, W.M., Conner, M. and Murray, T.C. (2008), "Distinguishing among perceived control, perceived difficulty and self- efficacy as determinants of intentions and behaviors", British Journal of Social Psychology, vol. 22, no. 3, pp. 218-233.

12. Sparks, P. and Shepherd, R. (1992), "Self-identity and the theory of planned behavior: Assessing the role of identification with 'Green consumerism'", Social Psychology Quarterly, vol. 55, no. 4, pp. 394.

13. Terry, D. J., Hogg, M.A. and White, K.M. (1991), "The theory of planned behavior: Self-identity, social identity and group norms", British journal of Social Psychology, vol. 38, pp. 227.

14. Wicker, A.W. (1969), “Attitudes versus actions: The relationship of verbal and overt behavioral responses to attitude objects." Journal of Social Issues, vol. 25, pp. $41 \sim 78$.

15. Yoon, C. (2011), "Theory of planned behavior and ethics theory in digital piracy: An integrated model", Journal of Business Ethics, vol. 100, pp. 405-417. 